\title{
Article \\ Relationship between Endothelial Function, Antiretroviral Treatment and Cardiovascular Risk Factors in HIV Patients of African Descent in South Africa: A Cross-Sectional Study
}

\author{
Benedicta N. Nkeh-Chungag ${ }^{1} \mathbb{D}$, Nandu Goswami ${ }^{2, *}$, Godwill A. Engwa ${ }^{1}$, Constance R. Sewani-Rusike ${ }^{3}$, \\ Vuyolwethu Mbombela ${ }^{3}$, Ingrid Webster ${ }^{4}$, Patrick De Boever ${ }^{5,6,7}{ }^{\circ}$, Harald H. Kessler ${ }^{8}$, Evelyn Stelzl ${ }^{8}$ \\ and Hans Strijdom ${ }^{4}$ (i)
}

check for updates

Citation: Nkeh-Chungag, B.N.;

Goswami, N.; Engwa, G.A.; Sewani-Rusike, C.R.; Mbombela, V.; Webster, I.; De Boever, P.; Kessler, H.H.; Stelzl, E.; Strijdom, H. Relationship between Endothelial Function, Antiretroviral Treatment and Cardiovascular Risk Factors in HIV Patients of African Descent in South Africa: A Cross-Sectional Study. J. Clin. Med. 2020, 10, 392.

https://dx.doi.org/

10.3390/jcm10030392

Received: 13 November 2020

Accepted: 8 December 2020

Published: 20 January 2021

Publisher's Note: MDPI stays neutral with regard to jurisdictional claims in published maps and institutional affiliations.

Copyright: () 2020 by the authors. Licensee MDPI, Basel, Switzerland. This article is an open access article distributed under the terms and conditions of the Creative Commons Attribution (CC BY) license (https: / / creativecommons.org/ licenses/by/4.0/).
1 Department of Biological and Environmental Sciences, Faculty of Natural Sciences, Walter Sisulu University PBX1, 5117 Mthatha, South Africa; bnkehchungag@wsu.ac.za (B.N.N.-C.); gengwa@wsu.ac.za (G.A.E.)

2 Physiology Division, Otto Loewi Research Center for Vascular Biology, Immunology and Inflammation, Medical University of Graz, Neue Stiftingtalstrasse 6, D-5 A 8036 Graz, Austria

3 Department of Human Biology, Faculty of Health Sciences, Walter Sisulu University PBX1, 5117 Mthatha, South Africa; crusike@wsu.ac.za (C.R.S.-R.); vuyombo@gmail.com (V.M.)

4 Centre for Cardio-Metabolic Research in Africa, Division of Medical Physiology, Faculty of Medicine and Health Sciences, Stellenbosch University, PO Box 241, 8000 Cape Town, South Africa; iwebster@sun.ac.za (I.W.); jgstr@sun.ac.za (H.S.)

5 Department of Biology, University of Antwerp, 2610 Wilrijk, Belgium; Patrick.DeBoever@uantwerpen.be

6 Centre for Environmental Sciences, Hasselt University, 3590 Diepenbeek, Belgium

7 Health Unit, Flemish Institute for Technological Research (VITO), $2400 \mathrm{Mol}$, Belgium

8 Diagnostic \& Research Institute of Hygiene, Microbiology and Environmental Medicine, Medical University of Graz, Neue Stiftingtalstrasse 6, AT-8010 Graz, Austria; harald.kessler@medunigraz.at (H.H.K.); evelyn.stelzl@medunigraz.at (E.S.)

* Correspondence: nandu.goswami@medunigraz.at

Abstract: Limited information on the effect of antiretroviral treatment (ART) on vascular function in South Africans of African descent living with human immunodeficiency virus (HIV) is available. The relationship between ART, vascular function and cardiovascular risk factors in South Africans of African ancestry with HIV was therefore studied. This cross-sectional study recruited $146 \mathrm{HIV}$ positive individuals on $\mathrm{ART}\left(\mathrm{HIV}^{+} \mathrm{ART}^{+}\right), 163 \mathrm{HIV}$-positive individuals not on $\mathrm{ART}\left(\mathrm{HIV}^{+} \mathrm{ART}^{-}\right)$ and 171 individuals without $\mathrm{HIV}\left(\mathrm{HIV}^{-}\right)$in Mthatha, Eastern Cape Province of South Africa. Flowmediated dilation (FMD) test was performed to assess endothelial function. Anthropometry and blood pressure parameters were measured. Lipid profile, glycaemic indices, serum creatinine as well as CD4 count and viral load were assayed in blood. Urinary albumin to creatinine ratio (ACR) was determined as a marker of cardiovascular risk. Obesity and albuminuria were positively associated with HIV, and $\mathrm{HIV}^{+} \mathrm{ART}^{+}$participants had significantly higher HDL cholesterol. Dyslipidaemia markers were significantly higher in hypertensive $\mathrm{HIV}^{+} \mathrm{ART}^{+}$participants compared with the controls $\left(\mathrm{HIV}^{+} \mathrm{ART}^{-}\right.$and $\mathrm{HIV}^{-}$participants). FMD was not different between $\mathrm{HIV}^{+} \mathrm{ART}^{+}$participants and the controls. Moreover, $\mathrm{HIV}^{+} \mathrm{ART}^{+}$participants with higher FMD showed lower total cholesterol and LDL cholesterol comparable to that of $\mathrm{HIV}^{-}$and $\mathrm{HIV}^{+} \mathrm{ART}^{-}$participants. A positive relationship between FMD and CD4 count was observed in $\mathrm{HIV}^{+} \mathrm{ART}^{+}$participants. In conclusion, antiretroviral treatment was associated with cardiovascular risk factors, particularly dyslipidaemia, in hypertensive South Africans of African ancestry with HIV. Although, ART was not associated with endothelial dysfunction, flow-mediated dilatation was positively associated with CD4 count in HIV-positive participants on ART.

Keywords: human immunodeficiency virus; antiretroviral treatment; cardiovascular disease; endothelial function; obesity; hypertension 


\section{Introduction}

Global reports show that approximately 17.9 million deaths recorded globally are due to cardiovascular diseases (CVDs) [1]. Notably, 75\% of these deaths occur in low- and middle-income countries [1]. Additionally, approximately 1 million deaths were attributed to CVDs in sub-Saharan Africa alone in 2013, which constituted 5.5\% of all global CVDrelated deaths. The burden of CVDs has been projected to double in sub-Saharan Africa by 2030 [2], In South Africa, CVDs are estimated to account for $18 \%$ mortality [3], which is linked to the increased prevalence of cardiovascular risk factors, particularly obesity and hypertension [4,5]. People living with HIV (PLHIV) may be at increased risk of stroke, myocardial infarction, atherosclerosis and chronic kidney disease development as a result of increased traditional cardiovascular risk factors [6,7]. A recent meta-analysis and systematic review reported that the crude rate of CVDs in PLHIV was 61.8 per 10,000 person-years, suggesting that PLHIV were twice as likely to develop CVDs within sub-Saharan Africa, presenting the most disability-adjusted life year (DALY) loss of 0.87 million [8]. The prevalence of cardiovascular risk factors in HIV continues to rise creating a major public health concern in South Africa [9].

Cardiovascular risk in HIV is a complex interplay of several factors. Studies show that obesity and dyslipidaemia are prevalent in HIV patients [10]. Hypertension is becoming a growing problem in adults with HIV. A 6-year prospective cohort study with over 80,000 HIV-infected persons showed that HIV-infected adults with hypertension had a 2-fold higher risk of developing acute myocardial infarction than uninfected adults with hypertension [11]. While traditional risk factors such as obesity, dyslipidaemia, hyperglycaemia and hypertension are known causes of CVD, recent evidence suggests that HIV-associated inflammation, oxidative stress and endothelial dysfunction are important mediators [12,13].

Endothelial dysfunction, resulting in altered vasodilation, endothelium-mediated vasomotor and anti-inflammatory responses [14], is an initiator and early marker for atherosclerosis [15]. Endothelial (dys)function can be assessed by flow-mediated dilation (FMD) of the brachial artery [16]. Although endothelial dysfunction has been associated with CVDs [17], the relationship of HIV infection with endothelial dysfunction needs further clarification [18]. Studies postulated that pro-inflammatory cytokines and immune mediators in HIV may induce endothelial cell injury [10] or HIV-1 virus and its component proteins may directly injure the endothelium resulting in endothelial dysfunction [19]. Furthermore, it is proposed that HIV-induced dyslipidaemia and metabolic syndrome may cause endothelial dysfunction [20].

The introduction and increased use of antiretroviral treatment (ART) has greatly reduced the global burden of HIV / AIDS. There has been a dramatic decline in immunodeficiencyrelated events, including deaths, in HIV-infected individuals [21,22]. In South Africa, there are over 7.2 million PLHIV and more than $50 \%$ of them are on ART medication [23]. Although the use of ART has substantially increased the life expectancy in South Africa, several reports have documented increased prevalence of cardiovascular risk factors, such as obesity, elevated blood sugar, elevated blood pressure, hypertriglyceridaemia and low high-density lipoprotein cholesterol (HDL-c) in PLHIV on ART [24]. ART has also been reported to promote platelet reactivity, a condition which has been implicated in the pathogenesis of atherothrombosis and CVDs [25]. Moreover, there is growing concern that the metabolic complications associated with HIV and ART may lead to an increased risk for CVDs [26].

There is also paucity of information on the effects of ART on vascular function in sub-Saharan Africa [27]. Though South Africa has the greatest global burden of HIV, there is limited information on the effect of ART on vascular function in South Africans of African ancestry who have the greatest burden of the disease in the country. Therefore, the aim of the current study was to specifically assess the relationship between ART, endothelial function and cardiovascular risk factors in a South African population of African ancestry. 


\section{Materials and Methods}

\subsection{Study Design and Population}

This was a cross-sectional study that involved adult ( $\geq 18$ years) South Africans of African ancestry with/without HIV attending the Gateway Clinic, a primary healthcare centre in Mthatha, Eastern Cape Province. Study participants were randomly recruited between June 2016 and December 2019. Participants who were HIV-positive $\left(\mathrm{HIV}^{+}\right)$and currently on ART medication $\left(\mathrm{HIV}^{+} \mathrm{ART}^{+}\right)$were classified separately from participants who were newly diagnosed with HIV and not yet on $\mathrm{ART}\left(\mathrm{HIV}^{+} \mathrm{ART}^{-}\right)$, while those who were HIV-negative $\left(\mathrm{HIV}^{-}\right.$) served as control. Participants considered $\mathrm{HIV}^{+} \mathrm{ART}^{+}$are those who had received ART for $\geq 4$ months. Participants were tested and their HIV status was confirmed before allocation to any of the study groups, and appropriate pre- and post-test counselling was performed. This study was part of the EndoAfrica South African Project [28]. Based on the protocol of the EndoAfrica study [28], this study had sufficient power to demonstrate 1-2\% effect size in FMD endothelial function measurement $(80 \%$ statistical power and 5\% significance) when including 450 participants, of which 150 were $\mathrm{HIV}^{-}$and 300 were $\mathrm{HIV}^{+}\left(\mathrm{HIV}^{+} \mathrm{ART}^{-}\right.$and $\left.\mathrm{HIV}^{+} \mathrm{ART}^{+}\right)$.

\subsection{Inclusion/Exclusion Criteria}

Male or female adults above 18 years old of African ancestry who had fasted, were either HIV positive or negative at the time of recruitment and were attending the Gateway Clinic in Mthatha without any severe illness or complications were recruited for the study. Participants who were critically ill with or without fever, pregnant, lactating, severely anaemic, physically challenged especially in the right arm used for flow mediated dilation test, had not fasted and individuals of non-African ancestry were excluded from the study. Participants who had smoked or exercised in the past $4 \mathrm{~h}$ were also excluded from the study.

\subsection{Ethical Approval}

This study was conducted in accordance with the principles stated in the Declaration of Helsinki (reviewed version of 2008) as well as local and national regulations in South Africa. Ethical approval was obtained from the Health Sciences Ethics Committee of Walter Sisulu University, South Africa (Ref No:005/2015). After careful explanation of the study aims and methods, written informed consent was obtained from participants before recruitment into the study. The study adhered to the standards of reporting and in accordance with the National Data Protection Act, wherein each participant was assigned a code and data/samples were stored anonymously.

\subsection{Data Collection}

A validated interviewer-administered questionnaire was adopted from the WHO STEPwise approach to Surveillance (STEPS) guidelines for non-communicable diseases (NCDs) [29]. It was modified accordingly to fit the aim of the study to obtain information on demographics, lifestyle factors such as smoking and alcohol consumption, physical activity, diet, information on HIV status, ART administration and family history of cardiovascular disease (CVD) risk factor assessment.

\subsection{Anthropometric Measurements}

Anthropometric measurements were performed in accordance with the International Standards for Anthropometric Assessments [30] on all participants. Waist circumference (WC) and hip circumference (HC) were measured using an anthropometric tape in centimetres $(\mathrm{cm})$ and waist-to-hip ratio (WHR) was calculated. Height was measured using a wall-mounted Harpenden stadiometer (version 602, SERITEX) and recorded to the nearest $0.1 \mathrm{~cm}$. Weight was measured using an Omron bioimpedance scale (OMRON BR511) and the body mass index (BMI) was calculated. The WHO classification for obesity by WHR in adults [31] was used to classify obesity as WHR $\geq 0.90 \mathrm{~cm}$ for men or $\geq 0.85 \mathrm{~cm}$ for women. 


\subsection{Blood Pressure Measurements}

Blood pressure was measured in a quiet room using the Omron automated sphygmomanometer (HBP-1100; Omron Healthcare Co. Ltd., Kyoto, Japan). After resting for 5 min, arm-size-appropriate cuffs were fitted to the upper arm and systolic blood pressure (SBP), diastolic blood pressure (DBP) and heart rate (HR) were measured trice automatically at 2 min intervals and the average of the three readings was computed. Hypertension was classified as SBP $\geq 140 \mathrm{mmHg}$ and/or DBP $\geq 90 \mathrm{mmHg}$ [32].

\subsection{Blood Collection and Biochemical Analysis}

Fasting blood and urine samples were collected. Serum was obtained after centrifugation and the fasting glucose (FG), glycated haemoglobin (HbA1c), triglycerides (TG), total cholesterol (TC), low-density lipoprotein cholesterol (LDL-c), high-density lipoprotein cholesterol (HDL-c), blood creatinine, CD4 count and HIV viral load were determined. Urine creatinine and albumin were quantified from early morning urine samples and the albumin-to-creatinine ratio (ACR) was calculated. The FG, HBA1c, CD4 count, TC, TG, LDL-c, creatinine and urea were determined using a cobas 501/502 panel/system (Roche Diagnostics, Indianapolis, IN, USA) according to the manufacturer's protocol, while HDL-c was calculated using the Friedewald equation. The cobas 6800/8800 HIV-1 test (Roche Diagnostic, USA) was used to determine HIV viral load by quantifying RNA copies according to the manufacturer's protocol. All assays were performed in the clinical pathology, haematology and virology units of the National Health Laboratory Service (NHLS) of the Nelson Mandela Academic Hospital, Walter Sisulu University, Mthatha, South Africa. Lipid profile measures were classified as high when TC $\geq 6.2 \mathrm{mmol} / \mathrm{L}$, LDL-c $\geq 4.15 \mathrm{mmol} / \mathrm{L}$ and TG $\geq 1.7$; and low when HDL-c $\leq 0.90 \mathrm{mmol} / \mathrm{L}$ according to the Adult Treatment Panel (ATP) III guideline [33]. Albuminuria (AU) was considered as ACR $>3 \mathrm{mg} / \mathrm{mmol}$ (equivalent to ACR $>30 \mathrm{mg} / \mathrm{g}$ ) according to the National Institute for Health and Clinical Excellence (NICE) guideline [34].

\subsection{Assessment of Vascular Function}

A mobile Esaote MyLab Five portable ultrasound device (Genoa, Italy) with an Esaote Doppler probe (LA523, $12 \mathrm{MHz}$ ) connected to computerized software with edge detection technology (Cardiovascular Suite (CVS); Quipu, Pisa, Italy) was used to measure endothelium-dependent flow-mediated dilation (FMD) of the brachial artery. Participants who had fasted overnight and had not smoked or exercised for at least $4 \mathrm{~h}$ were asked to lie down on the exam bed in the supine position with their right arm placed on the probe holder of the CVS ultrasound. A blood pressure cuff was placed around the forearm, as close as possible to the elbow and participants rested for 5-10 min prior to FMD measurement. An electrostatic gel probe was used to scan through the upper right arm in a transverse plain to visualize the pulsating brachial artery. Once the brachial artery was visualized on the CVS ultrasound screen, the probe was fixed to the probe holder and maintained in place for the rest of the measurement. The CVS software was turned on for the baseline recording at rest which lasted for $60 \mathrm{~s}(1 \mathrm{~min})$, after which the artery was occluded by raising the blood pressure to $200 \mathrm{mmHg}$ and maintaining it at this level for $5 \mathrm{~min}$. At the end of the $5 \mathrm{~min}$, the cuff was deflated to allow blood to flow freely in the brachial artery for 2 min after which the recording was stopped. The software then automatically calculated baseline diameter (the diameter of the artery at rest), maximum diameter (the diameter of the artery at occlusion), recovery diameter, baseline shear rate, maximum shear rate and percentage FMD. FMD (\%) was calculated as the difference between maximum and baseline diameter, expressed as a percentage of baseline diameter. FMD (\%) was classified into interquartile ranges to assess cardiovascular risk factors exceeding critical threshold for endothelial function. Concordance in the operation of the device by operators was checked to ensure reproducibility of the technique. 


\subsection{Data and Statistical Analysis}

Statistical Package for Social Sciences (SPSS) version 23.0 (IBM Corp., Armonk, NY, USA) was used for data analysis. Descriptive statistics was employed and data were presented as mean \pm standard deviation (SD). Analysis of variance (ANOVA) was used to compare mean differences between $\mathrm{HIV}^{-}, \mathrm{HIV}^{+} \mathrm{ART}^{-}$and $\mathrm{HIV}^{+} \mathrm{ART}^{+}$participants. Multivariate analysis of variance (MANOVA) was done to assess the interaction of antiretroviral treatment with endothelial function, hypertension or obesity among study groups. The relationship of HIV and ART with cardiovascular risk factors was assessed using the Chi-square test of association. Pearson's correlation was used to assess relationship between endothelial function and CVD risk factors. The standardized beta coefficient $(\beta)$ was determined by stepwise linear multiple regression analysis adjusted for age, sex and smoking status to identify factors that are predictors of endothelial (dys)function. An alpha error $(\alpha)$ of 0.05 was taken and $p$-value $\leq 0.05$ was considered to be significant.

\section{Results}

\subsection{Characteristics of Study Population}

The baseline characteristics of the study population are shown in Table 1. A total of 841 individuals were approached for the study and only 480 individuals, who were eligible, consented to participate in the study. Among the 480 (238 females and 242 males) participants recruited for the study, 171 were $\mathrm{HIV}^{-}$participants, 146 were $\mathrm{HIV}^{+}$participants on $\mathrm{ART}\left(\mathrm{HIV}^{+} \mathrm{ART}^{+}\right)$and 163 were $\mathrm{HIV}^{+}$participants not on $\mathrm{ART}\left(\mathrm{HIV}^{+} \mathrm{ART}^{-}\right)$. Among the $146 \mathrm{HIV}^{+} \mathrm{ART}^{+}$participants, $120(82.2 \%)$ were on TEE (tenofovir disoproxil fumarate + emtricitabine + efavirenz), $11(7.5 \%)$ on TLD (tenofovir disoproxil fumarate + lamivudine + dolutegravir), $7(4.8 \%)$ on zidovudine + lamivudine + efavirenz, $3(2.1 \%)$ on stavudine + lamivudine + nevirapine, $3(2.1 \%)$ on zidovudine + didanosine + lopinavir/ritonavir and $2(1.4 \%)$ on zidovudine + lamivudine + lopinavir/ritonavir. The age and heights of the participants were different $(p<0.05)$ among the three study groups. The $\mathrm{HR}_{\text {of }} \mathrm{HIV}^{+} \mathrm{ART}^{+}$ participants was significantly $(p<0.001)$ lower than that of $\mathrm{HIV}^{+} \mathrm{ART}^{-}$and $\mathrm{HIV}^{-}$participants. HDL-c level was significantly $(p<0.01)$ increased in $\mathrm{HIV}^{+} \mathrm{ART}^{+}$participants compared with $\mathrm{HIV}^{+} \mathrm{ART}^{-}$participants. The CD4 count was significantly $(p<0.001)$ lower in $\mathrm{HIV}^{+} \mathrm{ART}^{-}$and $\mathrm{HIV}^{+} \mathrm{ART}^{+}$participants than in $\mathrm{HIV}^{-}$subjects. The HIV viral load was significantly $(p<0.01)$ lower in $\mathrm{HIV}^{+} \mathrm{ART}^{+}$participants than in $\mathrm{HIV}^{+} \mathrm{ART}^{-}$participants and $23.3 \%$ of the $\mathrm{HIV}^{+} \mathrm{ART}^{+}$participants had undetectable viral load levels.

\subsection{Relationship of HIV and ART with Cardiovascular Risk Factors}

The relationship of HIV and ART with cardiovascular risk factors is shown in Table 2. Seventy-one participants (14.8\%) in the study population were hypertensive, while $35.4 \%$ $(170 / 480)$ participants in the study population were obese. Among the participants, more $\mathrm{HIV}^{+} \mathrm{ART}^{-}$participants were obese compared with $\mathrm{HIV}^{-}$and $\mathrm{HIV}^{+} \mathrm{ART}^{+}$participants and thus, obesity was associated with $\operatorname{HIV}\left(\chi^{2}=18.8 ; p\right.$-value $\left.=<0.001\right)$. Fewer $\mathrm{HIV}^{+} \mathrm{ART}^{+}$ participants had low HDL-c compared with $\mathrm{HIV}^{-}$and $\mathrm{HIV}^{+} \mathrm{ART}^{-}$participants and thus, ART was associated with increased HDL-c $\left(\chi^{2}=14.74 ; p=0.022\right)$. More $\mathrm{HIV}^{+}$participants $(n=16)$ had albuminuria compared with $\mathrm{HIV}^{-}$participants $(n=1)$ and thus, albuminuria was associated with HIV status $\left(\chi^{2}=7.707, p=0.021\right)$.

\subsection{The Interaction between Hypertension and ART with Cardiovascular Risk Factors}

To assess the contribution of hypertension and ART on cardiovascular risk in participants, a two-way analysis of variance (ANOVA) was performed. A significantly increased TC $\left(\mathrm{F}_{(2,96)}=5.349 ; p=0.006\right)$ and LDL-c $\left(\mathrm{F}_{(2,96)}=5.675 ; p=0.005\right)$ level was observed in hypertensive $\mathrm{HIV}^{+} \mathrm{ART}^{+}$participants compared with the controls. The concentration of TG was also significantly higher $\left(\mathrm{F}_{(2,96)}=4.455 ; p=0.014\right)$ in hypertensive $\mathrm{HIV}^{+} \mathrm{ART}^{+}$ participants and hypertensive $\mathrm{HIV}^{-}$participants. These findings indicated that ART administration was associated with lipid abnormalities in hypertensive HIV participants on ART (Table 3). 
Table 1. Baseline characteristics of study population.

\begin{tabular}{|c|c|c|c|c|}
\hline & $\mathrm{HIV}^{-}$ & HIV $^{+}$ART $^{-}$ & $\mathrm{HIV}^{+} \mathrm{ART}^{+}$ & $p$-Value \\
\hline $\mathrm{N}$ & 171 & 163 & 146 & \\
\hline Smoking (P/A) & $42 / 128$ & $33 / 127$ & $28 / 118$ & 0.295 \\
\hline Diabetes $(\mathrm{P} / \mathrm{A})$ & $1 / 170$ & $1 / 162$ & $1 / 145$ & 0.993 \\
\hline Age (years) & $28.9 \pm 7.9$ & $31.9 \pm 6.9$ & $34.4 \pm 8.4$ & $<0.001$ \\
\hline Weight (kg) & $70.1 \pm 15.9$ & $66.9 \pm 14.9$ & $70.8 \pm 16.8$ & 0.077 \\
\hline Height $(\mathrm{cm})$ & $165.9 \pm 7.9$ & $163.13 \pm 7.3$ & $163.8 \pm 9.2$ & 0.006 \\
\hline $\mathrm{HC}(\mathrm{cm})$ & $103.3 \pm 13.2$ & $104.4 \pm 14.7$ & $100.6 \pm 15.2$ & 0.093 \\
\hline $\mathrm{WC}(\mathrm{cm})$ & $85.2 \pm 15.7$ & $88.9 \pm 16.2$ & $88.4 \pm 16.9$ & 0.091 \\
\hline BMI $\left(\mathrm{kg} / \mathrm{m}^{2}\right)$ & $25.5 \pm 6.1$ & $25.1 \pm 6.2$ & $26.5 \pm 6.9$ & 0.136 \\
\hline WHC & $0.9 \pm 0.5$ & $0.9 \pm 0.1$ & $0.9 \pm 0.1$ & 0.917 \\
\hline SBP (mmHg) & $124.6 \pm 18.1$ & $123.0 \pm 34.9$ & $121.5 \pm 25.9$ & 0.528 \\
\hline DBP (mmHg) & $81.7 \pm 12.5$ & $78.0 \pm 17.9$ & $79.9 \pm 19.3$ & 0.132 \\
\hline $\mathrm{HR}(\mathrm{bpm})$ & $77.3 \pm 25.8$ & $80.04 \pm 18.8$ & $65.9 \pm 23.4^{\mathrm{a}, \mathrm{b}}$ & $<0.001$ \\
\hline $\mathrm{TC}(\mathrm{mmol} / \mathrm{L})$ & $3.9 \pm 0.9$ & $3.9 \pm 0.9$ & $4.6 \pm 5.1$ & 0.114 \\
\hline HDL-c $(\mathrm{mmol} / \mathrm{L})$ & $1.3 \pm 0.4$ & $1.2 \pm 0.4$ & $1.4 \pm 0.5^{b}$ & 0.004 \\
\hline LDL-c (mmol/L) & $2.1 \pm 0.9$ & $2.2 \pm 0.8$ & $2.6 \pm 0.7$ & 0.557 \\
\hline TG (mmol/L) & $1.1 \pm 0.6$ & $1.1 \pm 0.6$ & $1.3 \pm 0.8$ & 0.058 \\
\hline $\mathrm{FG}(\mathrm{mmol} / \mathrm{L})$ & $4.9 \pm 0.6$ & $4.9 \pm 1.1$ & $5.3 \pm 0.9$ & 0.127 \\
\hline HBA1c (\%) & $5.4 \pm 0.4$ & $5.4 \pm 0.5$ & $5.4 \pm 0.4$ & 0.738 \\
\hline $\mathrm{BC}(\mu \mathrm{mol} / \mathrm{L})$ & $70.2 \pm 13.9$ & $66.0 \pm 14.2$ & $67.6 \pm 13.8$ & 0.072 \\
\hline $\mathrm{UC}(\mathrm{mmol} / \mathrm{L})$ & $14.2 \pm 7.9$ & $14.5 \pm 8.2$ & $12.6 \pm 5.8$ & 0.163 \\
\hline Albumin (mg/L) & $2.8 \pm 8.3$ & $22.4 \pm 38.2$ & $11.1 \pm 18.5$ & 0.011 \\
\hline $\mathrm{ACR}(\mathrm{mg} / \mathrm{mol})$ & $0.2 \pm 0.7$ & $1.2 \pm 5.0$ & $0.9 \pm 1.8$ & 0.062 \\
\hline eGFR ((mL/min) & $140.8 \pm 56.9$ & $136.9 \pm 47.6$ & $129.1 \pm 41.6$ & 0.273 \\
\hline CD4 count (cells $/ \mu \mathrm{L})$ & $941.2 \pm 1123.7$ & $425.0 \pm 328.7^{\mathrm{a}}$ & $519.9 \pm 273.8^{a}$ & $<0.001$ \\
\hline $\begin{array}{l}\text { Viral load }(1000 \\
\text { copies } / \mathrm{mL})\end{array}$ & - & $171.5 \pm 319$ & $27.8 \pm 132$ & 0.003 \\
\hline FMD $(\%)$ & $12.5 \pm 10.1$ & $14.5 \pm 10.4$ & $12.2 \pm 11.8$ & 0.162 \\
\hline
\end{tabular}

Analysis of variance was used for analysis. Results are expressed as mean \pm standard deviation (SD). HIV: human immunodeficiency virus, $\mathrm{HIV}^{+}$: HIV-positive subjects, $\mathrm{HIV}^{-}$: HIV-negative subjects, ART: antiretroviral treatment, $\mathrm{HIV}^{+} \mathrm{ART}^{-}$: HIV-positive participants not on ART, $\mathrm{HIV}^{+} \mathrm{ART}^{+}$: HIV-positive participants on ART, ${ }^{a}$ indicates significant difference with $\mathrm{HIV}^{-}$subjects, ${ }^{\mathrm{b}}$ indicates significant difference with $\mathrm{HIV}^{+} \mathrm{ART}^{-}$participants. P: present, A: absent, HC: hip circumference, WC: waist circumference, BMI: body mass index, WHR: waist-to-hip ratio, SBP: systolic blood pressure, DBP: diastolic blood pressure, HR: heart rate, TC: total cholesterol, HDL-c: high-density lipoprotein cholesterol, LDL-c: low-density lipoprotein cholesterol, TG: triglycerides, FG: fasting glucose, HBA1c: glycated haemoglobin, BC: blood creatinine, UC: urine creatinine, ACR: albumin-to-creatinine ratio; eGFR: glomerular filtration rate; FMD: flow-mediated dilation.

Table 2. Relationship between HIV, ART and cardiovascular risk factors.

\begin{tabular}{|c|c|c|c|c|c|c|c|}
\hline & & $\mathrm{HIV}^{-}(\%)$ & $\mathrm{HIV}^{+} \mathrm{ART}^{-}(\%)$ & $\mathrm{HIV}^{+} \mathrm{ART}^{+}(\%)$ & Total (\%) & $x^{2}$ & $p$-Value \\
\hline \multirow[t]{2}{*}{$\mathrm{BP}$} & Normal & $146(86.4)$ & $142(87.1)$ & $118(81.5 \%)$ & $406(85.1)$ & 0.342 & 0.843 \\
\hline & HT & 23 (13.6) & $21(12.9)$ & $27(18.5)$ & $71(14.9)$ & & \\
\hline \multirow[t]{2}{*}{ WHR } & Lean & $117(68.2)$ & $94(57.7)$ & $99(67.8)$ & 310 (64.6) & 18.77 & $<0.001$ \\
\hline & Obese & $54(31.8)$ & $69(42.3)$ & $47(32.2)$ & $170(35.4)$ & & \\
\hline \multirow[t]{2}{*}{$\mathrm{TC}$} & Normal & $106(92.2)$ & $121(92.1)$ & $82(87.2)$ & 309 (91.2) & 2.535 & 0.282 \\
\hline & High & $9(7.8)$ & $9(6.9)$ & $12(12.8)$ & $30(8.8)$ & & \\
\hline \multirow[t]{2}{*}{ HDL-c } & Normal & $160(93.0)$ & $147(90.2)$ & 141 (96.6) & 348 (93.1) & 14.74 & 0.022 \\
\hline & Low & $12(7.0)$ & $16(9.8)$ & $5(3.4)$ & $33(6.9)$ & & \\
\hline \multirow[t]{2}{*}{ LDL-c } & Normal & $166(96.5)$ & $156(95.7)$ & $142(97.3)$ & $464(96.5)$ & 11.69 & 0.069 \\
\hline & High & $6(3.5)$ & $7(4.3)$ & $4(2.7)$ & $17(3.5)$ & & \\
\hline \multirow[t]{2}{*}{ TG } & Normal & $162(94.2)$ & $151(82.6)$ & 131 (89.7) & $444(92.3)$ & 0.089 & 0.352 \\
\hline & High & $10(5.8)$ & $12(7.4)$ & $15(10.3)$ & 37 (7.7) & & \\
\hline \multirow[t]{2}{*}{$\mathrm{AU}$} & Normal & $170(99.4)$ & $155(95.1)$ & $138(94.5)$ & $464(96.5)$ & 7.707 & 0.021 \\
\hline & High & $1(0.6)$ & $8(4.9)$ & $8(5.5)$ & $17(3.5)$ & & \\
\hline
\end{tabular}

Chi-square test was used for analysis. $\mathrm{HIV}^{+} \mathrm{ART}^{-}$: HIV-positive participants not on ART, $\mathrm{HIV}^{+} \mathrm{ART}^{+}$: HIV-positive participants on ART. HIV: human immunodeficiency virus, $\mathrm{HIV}^{+}$: HIV-positive subjects, $\mathrm{HIV}^{-}$: HIV-negative subjects, WHR: waist-to-hip ratio, BP: blood pressure, HT: hypertension, HDL-c: high-density lipoprotein cholesterol, LDL-c: low-density lipoprotein cholesterol, TC: total cholesterol, TG: triglycerides; AU: albuminuria, $\chi^{2}$ : chi-square. 
Table 3. Effect of ART and hypertension on cardiovascular risk factors.

\begin{tabular}{|c|c|c|c|c|c|c|c|}
\hline \multirow[b]{2}{*}{ Group (n) } & \multicolumn{2}{|c|}{$\mathrm{HIV}^{-}$} & \multicolumn{2}{|c|}{ HIV $^{+}$ART $^{-}$} & \multicolumn{2}{|c|}{$\mathrm{HIV}^{+} \mathrm{ART}^{+}$} & \multirow[t]{2}{*}{$p$-Value } \\
\hline & NT (146) & HT (23) & NT (142) & HT (21) & NT (118) & HT (27) & \\
\hline BMI $\left(\mathrm{kg} / \mathrm{m}^{2}\right)$ & $26.2 \pm 6.2$ & $25.4 \pm 4.5$ & $22.3 \pm 2.8$ & $23.3 \pm 3.2$ & $23.9 \pm 4.1$ & $26.3 \pm 6.3$ & 0.649 \\
\hline WHC & $0.8 \pm 0.1$ & $0.8 \pm 0.1$ & $0.8 \pm 0.2$ & $0.7 \pm 0.2$ & $0.8 \pm 0.1$ & $0.9 \pm 0.1$ & 0.566 \\
\hline $\mathrm{TC}(\mathrm{mmol} / \mathrm{L})$ & $3.9 \pm 0.9$ & $3.6 \pm 1.6$ & $4.2 \pm 1.2$ & $3.9 \pm 0.6$ & $4.1 \pm 0.9$ & $12.7 \pm 19.3$ & 0.006 \\
\hline HDL-c (mmol/L) & $1.3 \pm 0.4$ & $1.2 \pm 0.4$ & $1.2 \pm 0.4$ & $1.4 \pm 0.5$ & $1.4 \pm 0.3 \pm$ & $1.4 \pm 0.6$ & 0.652 \\
\hline LDL-c (mmol/L) & $2.1 \pm 0.7$ & $1.3 \pm 1.7$ & $2.5 \pm 0.9$ & $2.1 \pm 0.8$ & $2.1 \pm 0.8$ & $10.5 \pm 19.5$ & 0.005 \\
\hline $\mathrm{TG}(\mathrm{mmol} / \mathrm{L})$ & $1.0 \pm 0.4$ & $1.9 \pm 0.9$ & $1.2 \pm 0.6$ & $1.1 \pm 0.4$ & $1.2 \pm 0.4$ & $1.7 \pm 0.8$ & 0.014 \\
\hline $\mathrm{FBG}(\mathrm{mmol} / \mathrm{L})$ & $4.9 \pm 0.6$ & $4.9 \pm 0.3$ & $4.9 \pm 0.6$ & $5.1 \pm 0.9$ & $5.1 \pm 0.5$ & $5.3 \pm 0.4$ & 0.904 \\
\hline HBA1c (\%) & $5.3 \pm 0.4$ & $5.4 \pm 0.4$ & $5.4 \pm 0.2$ & $5.0 \pm 0.4$ & $5.6 \pm 0.4$ & $5.6 \pm 0.4$ & 0.096 \\
\hline $\mathrm{BC}(\mu \mathrm{mol} / \mathrm{L})$ & $68.6 \pm 11.6$ & $76.2 \pm 10.0$ & $73.0 \pm 19.9$ & $72.4 \pm 10.2$ & $74.0 \pm 13.6$ & $64.2 \pm 8.8$ & 0.176 \\
\hline $\mathrm{UC}(\mathrm{mmol} / \mathrm{L})$ & $13.8 \pm 6.9$ & $15.9 \pm 6.5$ & $15.8 \pm 8.5$ & $12.1 \pm 6.8$ & $13.5 \pm 6.4$ & $14.0 \pm 2.8$ & 0.448 \\
\hline Albumin (mg/L) & $3.8 \pm 11.7$ & $7.7 \pm 8.7$ & $1.9 \pm 2.2$ & $0.9 \pm 0.6$ & $2.6 \pm 3.3$ & $8.1 \pm 8.9$ & 0.539 \\
\hline $\mathrm{ACR}(\mathrm{mg} / \mathrm{mmol})$ & $0.3 \pm 0.9$ & $0.5 \pm 0.7$ & $0.1 \pm 0.2$ & $0.1 \pm 0.1$ & $0.3 \pm 0.5$ & $0.6 \pm 0.7$ & 0.789 \\
\hline FMD $(\%)$ & $12.6 \pm 10.3$ & $11.2 \pm 6.7$ & $13.5 \pm 9.8$ & $14.7 \pm 9.2$ & $11.4 \pm 19.1$ & $11.3 \pm 11.7$ & 0.939 \\
\hline
\end{tabular}

Multivariate analysis of variance (MANOVA) was used for analysis. Results are expressed as mean \pm SD. SD: standard deviation, NT: normotension, HT: hypertension, $\mathrm{HIV}^{+} \mathrm{ART}^{-}$: HIV-positive participants not on $\mathrm{ART}, \mathrm{HIV}^{+} \mathrm{ART}^{+}$: HIV-positive participants on ART. HIV: human immunodeficiency virus, $\mathrm{HIV}^{+}$: HIV-positive subjects, $\mathrm{HIV}^{-}$: HIV-negative subjects, BMI: body mass index, HC: hip circumference, WC: waist circumference, WHR: waist-to-hip ratio, SBP: systolic blood pressure, DBP: diastolic blood pressure, HR: heart rate, TC: total cholesterol, HDL-c: high-density lipoprotein cholesterol, LDL-c: low-density lipoprotein cholesterol, TG: triglycerides; FG: fasting glucose, HBA1c: glycated haemoglobin, BC: blood creatinine, UC: urinary creatinine, ACR: albumin-to-creatinine ratio; FMD: flow-mediated dilation.

\subsection{Relationship of Endothelial Function and ART With Cardiovascular Risk Factors in HIV}

FMD was classified into interquartile ranges to assess endothelial function in relationship with ART and cardiovascular risk factors. $\mathrm{HIV}^{+} \mathrm{ART}^{+}$participants with low FMD (second quartile) showed a significantly $(p<0.05)$ higher level of TC and LDL-c compared with $\mathrm{HIV}^{+} \mathrm{ART}^{-}$and $\mathrm{HIV}^{-}$participants. Moreover, $\mathrm{HIV}^{+} \mathrm{ART}^{+}$participants with higher FMD (third and fourth quartiles) showed lower TC and LDL-c comparable to that of $\mathrm{HIV}^{-}$and $\mathrm{HIV}^{+} \mathrm{ART}^{-}$participants. This implied that improved endothelial function was associated with reduced TC and LDL-c in HIV participants on ART (Table 4).

\subsection{Relationship between ART, Endothelial Function and Cardiovascular Risk Factors}

FMD was not associated with viral load $(r=-0.149 ; p=0.16)$ or cardiovascular risk factors (TC, TG, HDL-c, LDL-c, ACR, SBP, DSP and HR) in the overall cohort and various study groups. In addition, there was no correlation between FMD and CD4 count in $\mathrm{HIV}^{+} \mathrm{ART}^{-}$participants $(r=-0.072$; $p$-value $=0.579)$ or in $\mathrm{HIV}^{-}$participants $(r=0.062$; $p$-value $=0.807)$. However, a significant positive correlation $(r=0.250 ; p=0.023)$ was observed between FMD and CD4 count in $\mathrm{HIV}^{+} \mathrm{ART}^{+}$participants (Figure 1). Multiple linear regression analysis adjusted for age, sex and smoking showed no association of FMD with HIV viral load as well as cardiovascular risk factors. Moreover, adjusted stepwise linear regression analysis for a fitted model $(F=8.202 ; p=0.012)$ showed CD4 count as a positive predictor for FMD $\left(R^{2}=0.354\right.$; adjusted $R^{2}=0.31 ; \beta=0$. 595; $\left.p=0.023\right)$ in $\mathrm{HIV}^{+} \mathrm{ART}^{+}$participants, indicating that ART increases CD4 count which may improve endothelial function in HIV-infected individuals. 
Table 4. Relationship between ART, endothelial function and cardiovascular risk factors.

\begin{tabular}{|c|c|c|c|c|c|c|c|c|c|c|c|c|c|}
\hline \multirow[b]{2}{*}{ FMD $(n)$} & \multicolumn{4}{|c|}{ HIV $^{-}$} & \multicolumn{4}{|c|}{ HIV $^{+}$ART $^{-}$} & \multicolumn{4}{|c|}{ HIV $^{+}$ART $^{+}$} & \multirow[b]{2}{*}{$p$-Value } \\
\hline & 1st (41) & 2nd (38) & 3rd (38) & 4th (35) & 1st (25) & 2nd (36) & 3rd (41) & 4th (42) & 1st (37) & 2nd (37) & 3rd (31) & 4th (27) & \\
\hline BMI $\left(\mathrm{kg} / \mathrm{m}^{2}\right)$ & $26.8 \pm 6.2$ & $24.9 \pm 4.5$ & $26.9 \pm 7.1$ & $26.3 \pm 6.9$ & $22.5 \pm 3.2$ & $21.6 \pm 2.2$ & $21.9 \pm 2.9$ & $23.5 \pm 2.8$ & $24.1 \pm 3.7$ & $26.4 \pm 9.1$ & $26.6 \pm 4.3$ & $23.3 \pm 1.2$ & 0.886 \\
\hline WHR & $0.86 \pm 0.2$ & $0.79 \pm 0.19$ & $0.81 \pm 0.2$ & $0.79 \pm 0.1$ & $0.82 \pm 0.1$ & $0.86 \pm 0.1$ & $0.81 \pm 0.3$ & $0.73 \pm 0.3$ & $0.8 \pm 0.1$ & $0.91 \pm 0.1$ & $0.92 \pm 0.1$ & $0.81 \pm 0.1$ & 0.763 \\
\hline HDL-c $(\mathrm{mmol} / \mathrm{L})$ & $1.3 \pm 0.5$ & $1.3 \pm 0.4$ & $1.3 \pm 0.2$ & $1.4 \pm 0.5$ & $1.2 \pm 0.7$ & $1.3 \pm 0.1$ & $1.1 \pm 0.4$ & $1.4 \pm 0.3$ & $1.4 \pm 0.4$ & $1.4 \pm 0.6$ & $1.5 \pm 0.4$ & $1.3 \pm 0.3$ & 0.938 \\
\hline LDL-c (mmol/L) & $1.9 \pm 0.7$ & $2.0 \pm 1.2$ & $2.6 \pm 0.7$ & $1.9 \pm 0.7$ & $1.9 \pm 0.7$ & $2.5 \pm 0.8$ & $2.3 \pm 0.9$ & $2.8 \pm 1.3$ & $2.1 \pm 0.9$ & $14.1 \pm 24.09$ & $1.9 \pm 0.9$ & $3.1 \pm 1.4$ & 0.011 \\
\hline $\mathrm{TG}(\mathrm{mmol} / \mathrm{L})$ & $1.4 \pm 0.6$ & $1.0 \pm 0.5$ & $0.9 \pm 0.6$ & $1.0 \pm 0.4$ & $1.2 \pm 0.6$ & $1.2 \pm 0.4$ & $1.2 \pm 0.7$ & $1.1 \pm 0.4$ & $1.5 \pm 0.7$ & $1.7 \pm 0.3$ & $0.9 \pm 0.0$ & $0.9 \pm 0.3$ & 0.555 \\
\hline
\end{tabular}

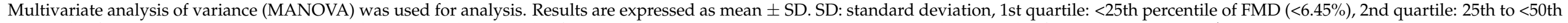

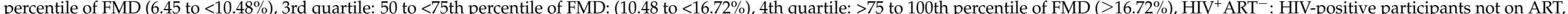

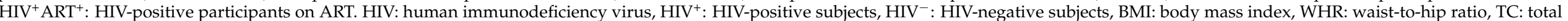
cholesterol, HDL-c: high-density lipoprotein cholesterol, LDL-c: low-density lipoprotein cholesterol, TG: triglycerides. 


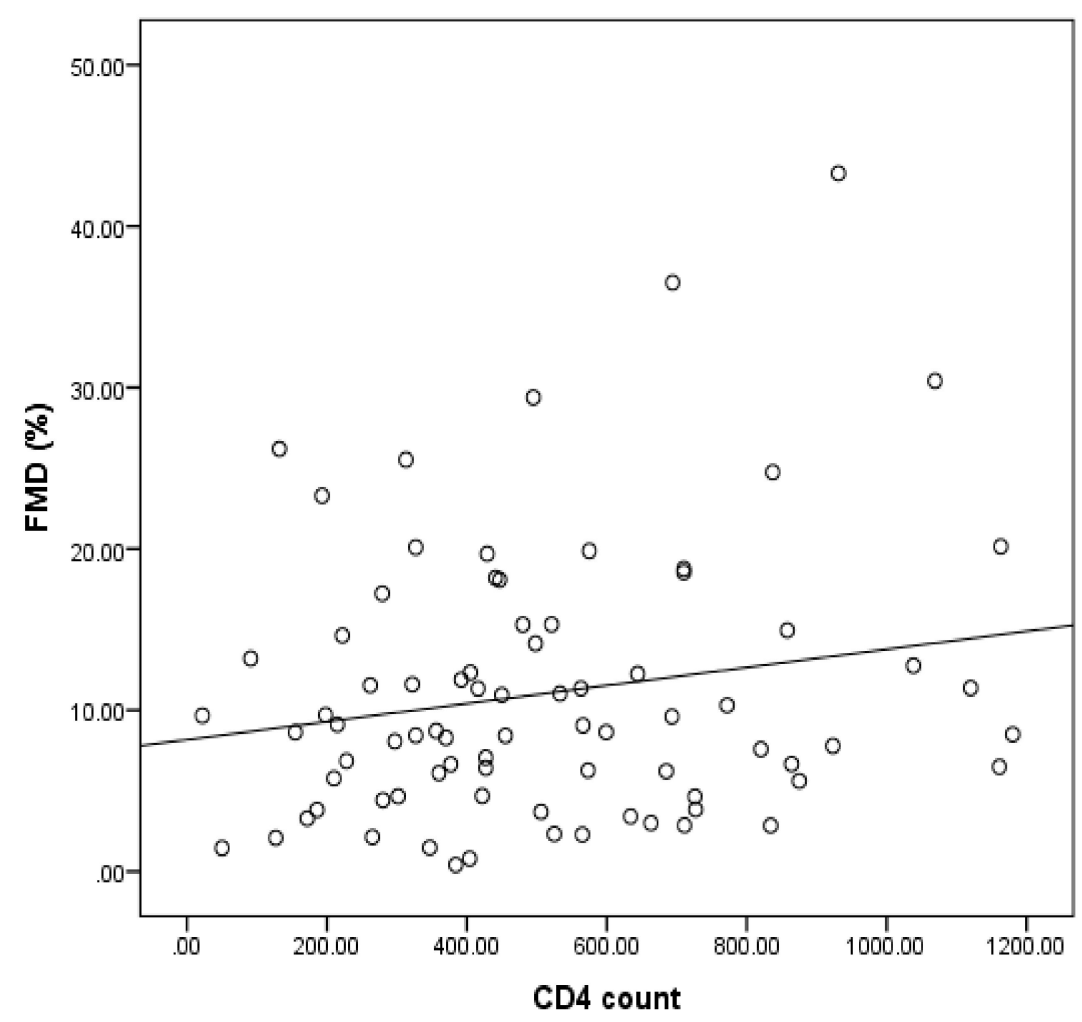

Figure 1. Relationship between FMD (\%) and CD4 count on HIV participants on ART. A significant positive correlation $(p<0.05)$ between FMD $(\%)$ and CD4 count was observed in HIV participants on ART.

\section{Discussion}

In this study, antiretroviral treatment was associated with cardiovascular risk factors, particularly dyslipidaemia, in hypertensive South Africans of African ancestry living with HIV. Previous studies have shown PLHIV to be at increased risk of CVDs $[35,36]$. Treatment with ART has also shown a positive association with cardiovascular risk factors in some studies [37,38], although findings from other studies have not been conclusive [39,40]. Some studies have shown that ART medication may impair vascular function in individuals with HIV in Western and Caucasian populations [41,42], but similar studies in African populations are not available. The lack of data on the subject in South Africans of African ancestry who present high prevalence of HIV prompted this study to investigate the relationship between HIV infection, ART and cardiovascular risk factors. This study showed no association between obesity and ART (Table 2). This finding is in contrast to previous studies [36,37]. However, a recent study in South Africa showed that the likelihood of an HIV patient on ART being obese was dependent on a longer duration of the treatment [43] and the type of ART administered as some ART do not promote lipogenesis. Therefore, the lack of association between ART and obesity in this study might have been affected by the duration of ART use and the type of ART administered. Obesity was positively associated with HIV in ART-naive patients (Table 2). Factors other than ART, such as smoking and alcohol, may be responsible for this association as has been reported in a previous study [44]. However, this finding is in agreement with some previous studies, which showed that cardiovascular risk factors, including obesity, are positively associated with HIV, although the association is usually not higher than that observed in individuals without HIV [45].

There have been reports that suggest ART as a major contributor to cardiovascular risk in PLHIV [46,47]. Certain ARTs have been shown to promote lipid abnormalities which are associated with CVDs $[48,49]$. Studies have shown that lopinavir/ritonavir (LPV/r) and fosamprenavir/ritonavir (FPV/r) are associated with increased plasma lipid levels [50]. 
Certain nucleoside/nucleotide reverse transcriptase inhibitors (NRTIs), including stavudine, abacavir and zidovudine, have been associated with dyslipidaemia, while tenofovir disoproxil fumarate (TDF) or tenofovir alafenamide fumarate (TAF) has been shown to favour lipogenesis [51]. Efavirenz, which belongs to the non-NRTIs, has been associated with increased triglyceride and total cholesterol levels [52]. Findings in this present study showed increased TC, LDL-c and TG levels in hypertensive $\mathrm{HIV}^{+} \mathrm{ART}^{+}$participants compared with the controls $\left(\mathrm{HIV}^{+} \mathrm{ART}^{-}\right.$and $\mathrm{HIV}^{-}$participants), suggesting a positive association between ART and dyslipidaemia in hypertensive PLHIV on ART (Table 3). This finding suggested that ART may increase lipids and cholesterol as previously reported [48], which may in turn promote a pro-atherosclerotic process and arterial stiffness, leading to an increase in blood pressure. Our findings are in agreement with previous studies, which have shown that some ART drug classes, particularly the NRTIs such as zidovudine and TDF, are associated with lipid abnormalities [49,51]. However, it remains unclear why such an association was observed mostly in hypertensive HIV participants on ART. The lack of association between ART and obesity in this study may be a result of the low use of dolutegravir (DTG)-based combination regiments, especially with TAF, which has been shown to be associated with weight gain and clinical obesity [53]. However, HDL-c was higher in $\mathrm{HIV}^{+} \mathrm{ART}^{+}$participants compared with $\mathrm{HIV}^{+} \mathrm{ART}^{-}$individuals (Table 1). This suggested that ART may favourably improve HDL-c levels in circulation. Considering the importance of HDL in the removal of cholesterol from circulation [54], ART in this study may have beneficial effects in cholesterol management due to the increased HDL-c level. A few studies have confirmed an elevated HDL-c level in $\mathrm{HIV}^{+} \mathrm{ART}^{+}$individuals, suggesting a protective role [55,56], while other studies have shown ART to reduce HDL-c in HIV-infected patients $[24,57]$ as opposed to the findings obtained in this study.

Albuminuria is another independent cardiovascular risk factor and has been associated with CVDs. Indeed, ACR, a measure for albuminuria, is a marker of renal function and cardiovascular risk [58]. A 10-fold as well as a 5-fold increase in urine albumin level, characteristic of albuminuria, was observed in $\mathrm{HIV}^{+} \mathrm{ART}^{+}$and $\mathrm{HIV}+\mathrm{ART}^{-}$participants, respectively, compared with $\mathrm{HIV}^{-}$participants. Moreover, there was a trend of reduced $\mathrm{ACR}$ and albumin in $\mathrm{HIV}^{+} \mathrm{ART}^{+}$participants compared with their $\mathrm{HIV}^{+} \mathrm{ART}^{-}$counterparts (Table 1). The proportion of albuminuria in $\mathrm{HIV}^{+}$individuals on/not on ART was also higher compared with $\mathrm{HIV}^{-}$individuals, translating to an association between HIV infection and albuminuria (Table 2). This finding suggested that albuminuria, which was associated with HIV, may be improved by ART as previously reported [59]. This finding agrees with a few studies which have shown the proportion of albuminuria to be high in persons with HIV [60,61].

Endothelial dysfunction is one of the key steps that contributes to the initiation and clinical manifestations of atherosclerosis and known to be an early predictor of future cardiovascular events in patients with or without a known cardiovascular risk [16,62]. Some studies have shown associations between HIV infection and endothelial dysfunction [10] and impaired endothelial function has previously been shown in HIV-infected individuals on ART [63] as well as in obese animals treated with antiretroviral drugs [64]. However, this finding remains controversial as some studies have not been able to establish an association between ART and endothelial dysfunction [65]. The findings in this study did not suggest that HIV or ART might affect endothelial function as flow mediated-dilation was not different between $\mathrm{HIV}^{+} \mathrm{ART}^{+}, \mathrm{HIV}^{+} \mathrm{ART}^{-}$and $\mathrm{HIV}^{-}$participants (Table 1). The underlying reason explaining this observation is not known. We speculate that duration of ART treatment, types of ART regimens and ethnicity may play a role. In this context, we provided one of the first observations for an African population and follow-up studies should further challenge our findings. This study also showed that, although TC and LDL-c were higher in $\mathrm{HIV}^{+} \mathrm{ART}^{+}$participants with low FMD (second quartile) compared with $\mathrm{HIV}^{+} \mathrm{ART}^{-}$and $\mathrm{HIV}^{-}$participants, $\mathrm{HIV}^{+} \mathrm{ART}^{+}$participants with higher FMD (third and four quartiles) showed lower TC and LDL-c comparable to that of $\mathrm{HIV}^{-}$and $\mathrm{HIV}^{+} \mathrm{ART}^{-}$ participants (Table 4). This indicated that reduced endothelial function may be associated 
with lipid abnormality, while improved endothelial function may reduce lipid abnormality in HIV participants. There was also a positive relationship between FMD and CD4 count in $\mathrm{HIV}^{+} \mathrm{ART}^{+}$participants (Figure 1 ) and $\mathrm{CD} 4$ count showed approximately a 0.6 chance ( $\beta=0.595)$ to improve endothelial function, that is, increased CD4 count was independently associated with improved endothelial function. This finding suggested that ART may improve CD4 count, which can ameliorate endothelial dysfunction in HIV subjects. A possible explanation for this observation is that ART may help to reduce HIV viral load (evident by the increased CD4 count), which has been suggested to cause endothelial damage [19]. Therefore, reduced HIV viral load in tissues, which is accompanied by increased CD4 count, may reduce endothelial damage.

Several influencing participant-related covariates and environmental factors could lead to low reproducibility of FMD measurements [66], but strict adherence to operating guidelines has been shown to provide reliable FMD measurements [67-69]. Therefore, in this study, we ensured reproducible measurements and a low coefficient of variation for FMD by executing the standard operating procedures described in the aforementioned papers as well as by Strijdom and colleagues [28]. Aspects such as limiting the number of operators, extensive training of the operator, measuring the same brachial artery regions, analysis in a controlled environment at approximately the same time of the day and regular quality control of the data were observed. The study employed three operators for FMD measurements and they were checked to ensure the reproducibility of results. Though adherence to strict operating guidelines was applied, this study may have been limited by the fact that treatments that could affect FMD, such as anti-aggregants, anticoagulants or statins, were not accounted for. There was also a disparity in the ages of participants in the various study groups and as a cross-sectional study, conclusions on causality cannot be drawn. This study could not correct for the different ART regimens, as they differ in effect on cholesterol and other cardiovascular risk factors which could affect the overall findings. We performed multiple statistical testing to discover biological trends and thus, we increased the risk of false positives, and follow-up studies will need to confirm our findings.

\section{Conclusions}

Antiretroviral treatment was associated with cardiovascular risk factors, particularly dyslipidaemia, in hypertensive South Africans of African ancestry living with HIV, but it was not associated with endothelial function. Moreover, antiretroviral treatment was associated with increased HDL-c in HIV participants. Although ART was not associated with endothelial function, flow-mediated dilatation was positively associated with CD4 count in HIV-positive participants on ART. Considering that this was a cross-sectional study which may be limiting, there is a need for longitudinal studies in the future to further assess the relationship of ART with cardiovascular risk factors in this population.

Author Contributions: Conceptualization, B.N.N.-C., N.G., and H.S.; Data curation, V.M. and G.A.E.; Formal analysis, B.N.N.-C., C.R.S.-R. and G.A.E.; Funding acquisition, B.N.N.-C., H.S. and N.G.; Investigation, V.M., I.W. and G.A.E.; Methodology, V.M., I.W., B.N.N.-C. and H.S.; Supervision, C.R.S.-R., N.G., H.S., P.D.B. and B.N.N.-C.; Validation, H.H.K., P.D.B. and E.S.; Writing-original draft, G.A.E., V.M., C.R.S.-R. and B.N.N.-C.; Writing—review \& editing, G.A.E., N.G., H.S., H.H.K, E.S., P.D.B., C.R.S.-R. and B.N.N.-C. All authors have read and agreed to the published version of the manuscript.

Funding: The EndoAfrica-WSU study formed part of a broader consortium under the ERAfrica program of the European Union 7th Framework Program. Funding for this study was disbursed via the Department of Science and Innovation in South Africa (contract number DST/CON 0077/2014). PDB and NG received funding from the Belgian Science Policy in Belgium (grant number: BL/67/eranet03) and the Österreichische Agentur für internationale Mobilität und Kooperation in Bildung, Wissenschaft und Forschung, OeAD GmbH (ÖAD) in Austria (grant number: KEF-Projekt P202), respectively. The funders had no role in study design, data collection and analysis, decision to publish, or preparation of the manuscript. 
Acknowledgments: We wish to thank the participants of this study.

Conflicts of Interest: The authors declare no conflict of interest.

\section{References}

1. WHO. Cardiovascular Diseases (CVDs); World Health Organization: Geneva, Switzerland, 2017; Available online: https:/ / www. who.int/news-room/fact-sheets/detail/cardiovascular-diseases-(cvds) (accessed on 11 August 2020).

2. Keates, A.K.; Mocumbi, A.O.; Ntsekhe, M.; Sliwa, K.; Stewart, S. Cardiovascular disease in Africa: Epidemiological profile and challenges. Nat. Rev. Cardiol. 2017, 14, 273-293. [CrossRef]

3. WHF. Factsheet: Cardiovascular Diseases in South Africa. World Heart Federation (WHF). 2017. Available online: https: //www.world-heart-federation.org/wp-content/uploads/2017/05/Cardiovascular_diseases_in_South_Africa.pdf (accessed on 14 August 2020).

4. Cois, A.; Day, C. Obesity trends and risk factors in the South African adult population. BMC Obes. 2015, 2, 42. [CrossRef]

5. Berry, K.M.; Parker, W.; Mchiza, Z.J. Quantifying unmet need for hypertension care in South Africa through a care cascade: Evidence from the SANHANES, 2011-2012. BMJ Glob. Health 2017, 2, e00034. [CrossRef]

6. $\quad$ Feinstein, M.J.; Hsue, P.Y.; Benjamin, L.A.; Bloomfield, G.S.; Currier, J.S.; Freiberg, M.S.; Grinspoon, S.K.; Levin, J.; Longenecker, C.T.; Post, W.S. Characteristics, prevention, and management of cardiovascular disease in people living with HIV: A scientific statement from the American Heart Association. Circulation 2019, 140, e98-e124. [CrossRef]

7. Alonso, A.; Barnes, A.E.; Guest, J.L.; Shah, A.; Shao, I.Y.; Marconi, V. HIV infection and incidence of cardiovascular diseases: An analysis of a large healthcare database. J. Am. Heart Assoc. 2019, 8, e012241. [CrossRef] [PubMed]

8. Shah, A.S.V.; Stelzle, D.; Lee, K.K.; Beck, E.J.; Alam, S.; Clifford, S.; Longenecker, C.T.; Strachan, F.; Bagchi, S.; Whiteley, W.; et al. Global burden of atherosclerotic cardiovascular disease in people living with HIV: Systematic review and meta-analysis. Circulation 2018, 138, 1100-1112. [CrossRef] [PubMed]

9. Hyle, E.P.; Bekker, L.G.; Martey, E.B. Cardiovascular risk factors among ART-experienced people with HIV in South Africa. J. Int. AIDS Soc. 2019, 22, e25274. [CrossRef]

10. Bloomfield, G.S.; Hogan, J.W.; Keter, A. Hypertension and obesity as cardiovascular risk factors among HIV seropositive patients in Western Kenya. PLoS ONE 2011, 6, e22288. [CrossRef]

11. Armah, K.A.; Chang, C.C.; Baker, J.V.; Veterans Aging Cohort Study (VACS) Project Team. Prehypertension, hypertension, and the risk of acute myocardial infarction in HIV-infected and-uninfected veterans. Clin. Infect. Dis. 2014, 58, 121-129. [CrossRef]

12. Triant, V.A. Cardiovascular disease and HIV infection. Curr. HIV/AIDS Rep. 2013, 10, 199-206. [CrossRef]

13. Strijdom, H.; Goswami, N.; De Boever, P.; Espach, Y.; Webster, I. Determinants of endothelial function in a cohort of HIV-infected and HIV-free participants: The role of cardiovascular risk factors, biomarkers of inflammation and HIV-dependent parameters. Atherosclerosis 2018, 275, E127. [CrossRef]

14. Daiber, A.; Steven, S.; Weber, A.; Shuvaev, V.V.; Muzykantov, V.R.; Laher, I.; Li, H.; Lamas, S.; Münzel, T. Targeting vascular (endothelial) dysfunction. Br. J. Pharmacol. 2017, 74, 1591-1619. [CrossRef] [PubMed]

15. Park, K.-H.; Park, W.J. Endothelial dysfunction: Clinical implications in cardiovascular disease and therapeutic approaches. J. Korean Med. Sci. 2015, 30, 1213-1225. [CrossRef]

16. Corretti, M.C.; Anderson, T.J.; Benjamin, E.J. Guidelines for the ultrasound assessment of endothelial-dependent flow-mediated vasodilation of the brachial artery: A report of the International Brachial Artery Reactivity Task Force. J. Am. Coll. Cardiol. 2002, 39, 257-265. [CrossRef]

17. Widmer, R.J.; Lerman, A. Endothelial dysfunction and cardiovascular disease. Glob. Cardiol. Sci. Pract. 2014, 2014, 291-308. [CrossRef]

18. Francisci, D.; Giannini, S.; Baldelli, F. HIV type 1 infection, and not short-term HAART, induces endothelial dysfunction. AIDS 2009, 23, 589-596. [CrossRef]

19. Marincowitz, C.; Genis, A.; Goswami, N.; De Boever, P.; Nawrot, T.S.; Strijdom, H. Vascular endothelial dysfunction in the wake of HIV and ART. FEBS J. 2019, 286, 1256-1270. [CrossRef]

20. Monsuez, J.J.; Charniot, J.C.; Escaut, L. HIV associated vascular diseases: Structural and functional changes, clinical implications. Int. J. Cardiol. 2009, 133, 293-306. [CrossRef]

21. Collaboration Antiretroviral Therapy Cohort. Survival of HIV-positive patients starting antiretroviral therapy between 1996 and 2013: A collaborative analysis of cohort studies. Lancet HIV 2017, 4, e349-e356. [CrossRef]

22. Bor, J.; Herbst, A.J.; Newell, M.-L.; Bearnighausen, T. Increases in adult life expectancy in rural South Africa: Valuing the scale-up of HIV treatment. Science 2013, 339, 961-965. [CrossRef]

23. UNAIDS. Number of People Living with HIV. 2017. Available online: http:/ / aidsinfo.unaids.org/ (accessed on 1 February 2019).

24. Abrahams, Z.; Dave, J.A.; Maartens, G.; Levitt, N.S. Changes in blood pressure, glucose levels, insulin secretion and anthropometry after long term exposure to antiretroviral therapy in South African women. AIDS Res. Ther. 2015, 12, 24. [CrossRef] [PubMed]

25. Laurence, J.; Elhadad, S.; Ahamed, J. HIV-associated cardiovascular disease: Importance of platelet activation and cardiac fibrosis in the setting of specific antiretroviral therapies. Open Heart 2018, 5, e000823. [CrossRef] [PubMed]

26. Julius, H.; Basu, D.; Ricci, E.; Wing, J.; Basu, J.K.; Pocaterra, D. The burden of metabolic diseases amongst HIV positive patients on HAART attending The Johannesburg Hospital. Curr. HIV Res. 2011, 9, 247-252. [CrossRef] [PubMed] 
27. Strijdom, H.; De Boever, P.; Nawrot, T.S.; Goswami, N. HIV/AIDS: Emerging threat to cardiovascular health in sub-Saharan Africa. SAMJ S. Afr. Med. J. 2016, 106, 537. [CrossRef]

28. Strijdom, H.; De Boever, P.; Walz, G.; Essop, M.F.; Nawrot, T.S.; Webster, I.; Westcott, C.; Mashele, N.; Everson, F.; Malherbe, S.T.; et al. Cardiovascular risk and endothelial function in people living with HIV/AIDS: Design of the multi-site, longitudinal EndoAfrica study in the Western Cape Province of South Africa. BMC Infect. Dis. 2017, 17, 41. [CrossRef]

29. WHO. WHO STEPS Surveillance Manual: The WHO STEPwise Approach to Noncommunicable Disease Risk Factor Surveillance; World Health Organization: Geneva, Switzerland, 2017; Available online: https://www.who.int/ncds/surveillance/steps/STEPS_ Manual.pdf?ua=1 (accessed on 27 November 2020).

30. Stewart, A.; Marfell-Jones, M.; Olds, T.; Ridder, H. International Standards for Anthropometric Assessment; ISAK: Lower Hutt, New Zealand, 2011.

31. WHO. Waist Circumference and Waist-Hip Ratio: Report of a WHO Expert Consultation; World Health Organization: Geneva, Switzerland, 2008.

32. Giles, T.D.; Materson, B.J.; Cohn, J.N.; Kostis, J.B. Definition and classification of hypertension: An update. J. Clin. Hypertens. 2009, 11, 611-614. [CrossRef] [PubMed]

33. Expert Panel on Detection, Evaluation, and Treatment of High Blood Cholesterol in Adults. Executive Summary of the Third Report of the National Cholesterol Education Program (NCEP) Expert Panel on Detection, Evaluation, and Treatment of High Blood Cholesterol in Adults (Adult Treatment Panel III). JAMA 2001, 285, 2486-2497. [CrossRef]

34. NICE. Chronic Kidney Disease-Early Identification and Management of Chronic Kidney Disease in Adults in Primary and Secondary Care; National Institute for Health and Clinical Excellence (NICE): London, UK, 2014.

35. Islam, F.M.; Wu, J.; Jansson, J. Relative risk of cardiovascular disease among people living with HIV: A systematic review and meta-analysis. HIV Med. 2012, 13, 60-68. [CrossRef]

36. Neaton, J.D. HIV and cardiovascular disease: Comment on Islam. HIV Med. 2013, 14, 517-518. [CrossRef]

37. Bavinger, C.; Bendavid, E.; Niehaus, K. Risk of cardiovascular disease from antiretroviral therapy for HIV: A systematic review. PLoS ONE 2013, 8, e59551. [CrossRef]

38. Choi, A.I.; Vittinghoff, E.; Deeks, S.G. Cardiovascular risks associated with abacavir and tenofovir exposure in HIV-infected persons. AIDS 2011, 25, 1289-1298. [CrossRef] [PubMed]

39. Ribaudo, H.J.; Benson, C.A.; Zheng, Y. No risk of myocardial infarction associated with initial antiretroviral treatment containing abacavir: Short and long-term results from ACTG A5001/ALLRT. Clin. Infect. Dis. 2011, 52, 929-940. [CrossRef] [PubMed]

40. Brothers, C.H.; Hernandez, J.E.; Cutrell, A.G. Risk of myocardial infarction and abacavir therapy: No increased risk across 52 GlaxoSmithKline-sponsored clinical trials in adult subjects. J. Acquir. Immune. Defic. Syndr. 2009, 51, 20-28. [CrossRef] [PubMed]

41. De Gaetano, D.K.; Rabagliati, R.; Tumbarello, M.; Tacconelli, E.; Amore, C.; Cauda, R.; Lacoviello, L. Increased soluble markers of endothelial dysfunction in HIV-positive patients under highly active antiretroviral therapy. AIDS 2003, 17, 765-768. [CrossRef] [PubMed]

42. O’Halloran, J.A.; Dunne, E.; Gurwith, M.M.P.; Lambert, J.S.; Sheehan, G.J.; Feeney, E.R.; Pozniak, A.; Reiss, P.; Kenny, D.; Mallon, P.W.G. The effect of initiation of antiretroviral therapy on monocyte, endothelial and platelet function in HIV-1 infection. HIV Med. 2015, 16, 608-619. [CrossRef] [PubMed]

43. Mahlangu, K.; Modjadji, P.; Madiba, S. The nutritional status of adult antiretroviral therapy recipients with a recent HIV diagnosis; a cross-sectional study in primary health facilities in Gauteng, South Africa. Healthcare 2020, 8, 290. [CrossRef]

44. Obry-Roguet, V.; Brégigeon, S.; Cano, C.E.; Lions, C.; Zaegel-Faucher, O.; Laroche, H.; Galie, S.; De Lamarlière, P.G.; Orticoni, M.; Soavi, M.J.; et al. Risk factors associated with overweight and obesity in HIV-infected people: Aging, behavioral factors but not cART in a cross-sectional study. Medicine 2018, 97, e10956. [CrossRef]

45. Crum-Cianflone, N.F.; Roediger, M.; Eberly, L.E.; Vyas, K.; Landrum, M.L.; Ganesan, A.; Weintrob, A.C.; Barthel, R.V.; Agan, B.K.; Infectious Disease CLINICAL research Program HIV Working Group. Obesity among HIV-infected persons: Impact of weight on CD4 cell count. AIDS 2010, 24, 1069-1072. [CrossRef]

46. Rosenblatt, L.; Farr, A.M.; Nkhoma, E.T. Risk of cardiovascular events among patients with HIV treated with atazanavir containing regimens: A retrospective cohort study. BMC Infect. Dis. 2016, 16, 492. [CrossRef]

47. Desai, M.; Joyce, V.; Bendavid, E. Risk of cardiovascular events associated with current exposure to HIV antiretroviral therapies in a US veteran population. Clin. Infect. Dis. 2015, 61, 445-452. [CrossRef]

48. Foulkes, A.S.; Wohl, D.A.; Frank, I.; Puleo, E.; Restine, S. Associations among race/ethnicity, apoC-III genotypes, and lipids in HIV1-infected individuals on antiretroviral therapy. PLoS Med. 2006, 3, e52. [CrossRef] [PubMed]

49. Crane, H.M.; Grunfeld, C.; Willig, J.H.; Mugavero, M.J.; Van Rompaey, S.; Moore, R.; Rodriguez, B.; Feldman, B.J.; Lederman, M.M.; Saag, M.S. Impact of NRTIs on lipid levels among a large HIV-infected cohort initiating antiretroviral therapy in clinical care. AIDS 2011, 25, 185-195. [CrossRef] [PubMed]

50. Riddler, S.A.; Smit, E.; Cole, S.R. Impact of HIV infection and HAART on serum lipids in men. JAMA. 2003, 289, 2978-2982. [CrossRef] [PubMed]

51. INSIGHT Start Study Group; Lundgren, J.D.; Babiker, A.G. Initiation of antiretroviral therapy in early asymptomatic HIV infection. N. Engl. J. Med. 2015, 373, 795-807. [PubMed]

52. Babiker, A.G.; Emery, S.; Fatkenheuer, G. Considerations in the rationale, design and methods of the Strategic Timing of AntiRetroviral Treatment (START) study. Clin. Trials. 2013, 10, S5-S36. [CrossRef] 
53. Venter, W.D.F.; Moorhouse, M.; Sokhela, S.; Fairlie, L.; Mashabane, N.; Masenya, M.; Serenata, C.; Akpomiemie, G.; Qavi, A.; Chandiwana, N.; et al. Dolutegravir plus two different prodrugs of tenofovir to treat HIV. N. Engl. J. Med. 2019, 381, 803-815. [CrossRef]

54. Mineo, C.; Shaul, P.W. Novel biological functions of high-density lipoprotein cholesterol. Circ. Res. 2012, 111, 1079-1090. [CrossRef]

55. Adewole, O.O.; Eze, S.; Betiku, Y.; Anteyi, E.; Wada, I.; Ajuwon, Z.; Erhabor, G. Lipid profile in HIV/AIDS patients in Nigeria. Afri. Health Sci. 2010, 10, 144-149.

56. MacInnes, A.; Lazzarin, A.; Di Perri, G.; Sierra-Madero, J.G.; Aberg, J.; Heera, J.; Rajicic, N.; Goodrich, J.; Mayer, H.; Valdez, H. Maraviroc can improve lipid profiles in dyslipidemic patients with HIV: Results from the MERIT Trial. HIV Clin. Trials 2011, 12, 24-36. [CrossRef]

57. Bernal, E.; Masiá, M.; Padilla, S.; Gutiérrez, F. High-Density lipoprotein cholesterol in HIV-Infected patients: Evidence for an association with HIV-1 viral load, antiretroviral therapy status, and regimen composition. AIDS Patients Care STDs 2008, 22, 569-575. [CrossRef]

58. Singh, A.; Satchell, S.C. Microalbuminuria: Causes and implications. Pediatr. Nephrol. 2011, 26, 1957-1965. [CrossRef] [PubMed]

59. Szczech, L.A.; Grunfeld, C.; Scherzer, R.; Canchola, J.A.; van der Horst, C.; Sidney, S.; Wohl, D.; Shlipak, M.G. Microalbuminuria in HIV infection. AIDS 2007, 21, 1003-1009. [CrossRef] [PubMed]

60. Hadigan, C.; Edwards, E.; Rosenberg, A.; Purdy, J.B.; Fleischman, E.; Howard, L.; Mican, J.M.; Sampath, K.; Oyalowo, A.; Johnson, A. Microalbuminuria in HIV Disease. Am. J. Nephrol. 2013, 37, 443-451. [CrossRef]

61. Falasca, K.; Di Nicola, M.; Porfilio, I.; Ucceferri, C.; Schiaroli, E.; Gabrielli, C.; Francisci, D.; Vecchiet, J. Predictive factors and prevalence of microalbuminuria in HIV-infected patients: A cross-sectional analysis. BMC Nephrol. 2017, 18, 255. [CrossRef]

62. Barthelmes, J.; Nägele, M.P.; Ludovici, V.; Ruschitzka, F.; Sudano, I.; Flammer, A.J. Endothelial dysfunction in cardiovascular disease and Flammer syndrome-Similarities and differences. EPMA J. 2017, 8, 99-109. [CrossRef]

63. Bush, K.N.V.; Teel, J.L.; Watts, J.A. Association of endothelial dysfunction and antiretroviral therapy in early HIV infection. JAMA Netw. Open 2019, 2, e1913615. [CrossRef]

64. Kamau, F.; Strijdom, H.; Nwangi, P.; Blackhurst, D.; Imperial, E.; Salie, R. Antiretroviral drug-endothelial dysfunction is improved by dual PPAR $\alpha / \gamma$ stimulation in Obesity. Vasc. Pharmacol. 2019, 121, 106577. [CrossRef]

65. Dysangco, A.; Liu, Z.; Stein, J.H.; Dubê̂,, M.P.; Gupta, S.K. HIV infection, antiretroviral therapy, and measures of endothelial function, inflammation, metabolism, and oxidative stress. PLoS ONE 2017, 12, e0183511. [CrossRef]

66. Thijssen, D.H.; Black, M.A.; Pyke, K.E.; Padilla, J.; Atkinson, G.; Harris, R.A.; Parker, B.; Widlansky, M.E.; Tschakovsky, M.E.; Green, D.J. Assessment of flow-mediated dilation in humans: A methodological and physiological guideline. Am. J. Physiol. Heart Circ. Physiol. 2011, 300, H2-H12. [CrossRef]

67. Charakida, M.; De Groot, E.; Loukogeorgakis, S.P.; Khan, T.; Lüscher, T.; Kastelein, J.J.; Gasser, E.J. Variability and reproducibility of flow-mediated dilatation in a multicentre clinical trial. Eur. Heart J. 2013, 34, 3501-3507. [CrossRef]

68. Ghiadoni, L.; Faita, F.; Salvetti, M.; Cordiano, C.; Biggi, A.; Puato, M.; Di Monaco, A.; De Siati, L.; Volpe, M.; Ambrosio, G. Assessment of flow-mediated dilation reproducibility: A nationwide multicenter study. J. Hypertens. 2012, 30, $1399-1405$. [CrossRef]

69. Greyling, A.; Van Mil, A.C.; Zock, P.L.; Green, D.J.; Ghiadoni, L.; Thijssen, D.H.; TIFN International Working Group on Flow Mediated Dilation. Adherence to guidelines strongly improves reproducibility of brachial artery flow-mediated dilation. Atherosclerosis 2016, 248, 196-202. [CrossRef] 